\title{
Water immersion for post incident cooling of firefighters; a review of practical fire ground cooling modalities
}

\author{
Matt Brearley ${ }^{1 *}$ (D) and Anthony Walker ${ }^{2,3}$
}

\begin{abstract}
Rapidly cooling firefighters post emergency response is likely to increase the operational effectiveness of fire services during prolonged incidents. A variety of techniques have therefore been examined to return firefighters core body temperature to safe levels prior to fire scene re-entry or redeployment. The recommendation of forearm immersion $(\mathrm{HFI})$ in cold water by the National Fire and Protection Association preceded implementation of this active cooling modality by a number of fire services in North America, South East Asia and Australia. The vascularity of the hands and forearms may expedite body heat removal, however, immersion of the torso, pelvis and/or lower body, otherwise known as multi-segment immersion (MSI), exposes a greater proportion of the body surface to water than HFI, potentially increasing the rates of cooling conferred. Therefore, this review sought to establish the efficacy of HFI and MSI to rapidly reduce firefighters core body temperature to safe working levels during rest periods. A total of 38 studies with 55 treatments ( $43 \mathrm{MSI}, 12 \mathrm{HFI}$ ) were reviewed. The core body temperature cooling rates conferred by MSI were generally classified as ideal $(n=23)$ with a range of $\sim 0.01$ to $0.35^{\circ} \mathrm{C} \mathrm{min}^{-1}$. In contrast, all HFI treatments resulted in unacceptably slow core body temperature cooling rates $\left(\sim 0.01\right.$ to $\left.0.05^{\circ} \mathrm{C} \mathrm{min}^{-1}\right)$. Based upon the extensive field of research supporting immersion of large body surface areas and comparable logistics of establishing HFI or MSI, it is recommended that fire and rescue management reassess their approach to fireground rehabilitation of responders. Specifically, we question the use of HFI to rapidly lower firefighter core body temperature during rest periods. By utilising MSI to restore firefighter $T_{c}$ to safe working levels, fire and rescue services would adopt an evidence based approach to maintaining operational capability during arduous, sustained responses. While the optimal MSI protocol will be determined by the specifics of an individual response, maximising the body surface area immersed in circulated water of up to $26^{\circ} \mathrm{C}$ for $15 \mathrm{~min}$ is likely to return firefighter $T_{c}$ to safe working levels during rest periods. Utilising cooler water temperatures will expedite $T_{C}$ cooling and minimise immersion duration.
\end{abstract}

Keywords: Cooling, Core body temperature, Firefighter, Forearm, Heat, Immersion, Water

\section{Background}

Emergency firefighting requires firefighters to wear heavy, multilayered, impermeable personal protective clothing (PPC). While providing protection from radiant heat, flame and hazardous chemicals, PPC creates an uncompensable environment that actively limits dissipation of body heat [1]. The combination of hot

\footnotetext{
*Correspondence: matt.brearley@nt.gov.au

${ }^{1}$ National Critical Care and Trauma Response Centre, Level 8 Royal

Darwin Hospital, Rocklands Drive, Tiwi, NT 0810, Australia

Full list of author information is available at the end of the article
}

ambient temperatures and intense physical work leads to increases in core body temperature $\left(\mathrm{T}_{c}\right)$. Firefighting and rescue simulations, conducted with participants wearing $\mathrm{PPC}$, resulted in individual peak $\mathrm{T}_{\mathrm{c}}$ of $39.6-40.9^{\circ} \mathrm{C}$ [2-5], synonymous with exertional heat exhaustion in laboratory settings $[6,7]$. In the field, high $\mathrm{T}_{\mathrm{c}}$ would likely limit work output due to an acute impact on physiological [8] and psychological function [9]. High $\mathrm{T}_{\mathrm{c}}$ is also likely to be coupled with adverse immune and inflammatory activity [10-12]. To mitigate the risk of high $\mathrm{T}_{\mathrm{c}}$ precipitating fatigue and ultimately exertional heat illness, firefighters rotate between work tasks and rest breaks where feasible. 
Since firefighters are regularly tasked with re-entering fire scenes or are redeployed to other emergency work tasks, breaks can be restricted to less than 20 min between work bouts. In that time, to maintain operational readiness, firefighters are required to replenish their equipment and PPC prior to engaging in rehabilitative practices such as rehydration and cooling [13]. Hence, the development of rehabilitation protocols, inclusive of rapid and effective cooling modalities, is a pre-requisite to maximising the health, safety and performance of firefighters during sustained emergency responses.

To achieve rapid post-incident cooling of firefighters, a variety of modalities including ice vests [14-16], misting fans [2, 4], iced towels [17], crushed ice ingestion [2, 5], cool intravenous fluids [18], hand and/or forearm water immersion $[4,19-21]$ and whole or lower body water immersion $[2,5]$ have been investigated. Of these methods, the National Fire and Protection Association (NFPA), the peak advisory body in the USA recommends hand and forearm immersion (HFI) in cold water and use of misting fans as active cooling modalities for use in firefighting settings [22].

It is unclear how many fire services have implemented HFI based upon the NFPA recommendation, however, HFI is documented within rehabilitation guidelines of fire services in North America, South East Asia and Australia. The recommendation of HFI for post-incident cooling was based upon the research of Selkirk et al. [4]. That study demonstrated that HFI $\left(\sim 17{ }^{\circ} \mathrm{C}\right)$ was more effective in lowering core body temperature during a rest phase than a commercially available misting fan, or passive cooling in the form of seated rest in the shade $\left(35^{\circ} \mathrm{C}\right.$, $50 \%$ relative humidity). Despite support for HFI, an emerging field of research in Australia has demonstrated the effectiveness of lower body [5] and mid sternum depth water immersion [2] to lower $\mathrm{T}_{\mathrm{c}}$ of urban firefighters following simulated work tasks in the heat. Immersion of the torso, pelvis and/or lower body, referred to as multi segment immersion (MSI), exposes a greater proportion of the body surface to water than HFI, potentially increasing the rates of cooling conferred. However, the vascularity of the hands and forearms may expedite heat removal to offset the limitation of immersing a small surface area. Hence, it is currently unclear whether the outcomes of HFI and MSI make either a preferable option for field cooling of firefighters. Therefore, this review aims to establish the efficacy of water immersion of the hands and/or forearms, and immersion of multiple body segments in firefighting settings to rapidly reduce $T_{c}$ to safe working limits of less than $38.0^{\circ} \mathrm{C}$ [23].

\section{Methodology}

A computerised search of Pubmed, Google Scholar and SportDiscus was finalised in July 2015, using the following search terms: cold water, cold water immersion, cooling, cooling modality, cryotherapy, firefighter, forearm, forearm cooling, hand cooling, heat stress, heat stroke, ice bath, ice water immersion, physical activity, rehabilitation, torso and water immersion. Additional published studies known to the authors, and reference list searches of the retrieved studies complemented the initial examination. Inclusion in the present review was assessed against the following research criteria prior to data analysis; original research on human participants, body heat storage induced by physical activity, minimum pre-treatment $\mathrm{T}_{c}$ of $38.2{ }^{\circ} \mathrm{C}$ reflecting the lowest anticipated $\mathrm{T}_{\mathrm{c}}$ during arduous emergency responses, minimum of five continuous minutes of immersion, provision of sufficient detail to reproduce methodology and valid $\mathrm{T}_{\mathrm{c}}$ measurement. Specifically, those studies reporting tympanic temperature data were excluded due to lack of validity [24, 25].

For the purpose of this review, no distinction between hand and forearm immersion was made. It is acknowledged that the surface area of the hands (5\%) varies from the forearms (14\%) [26]. However, based upon similar logistics, cooling dynamics and the small number of studies meeting the inclusion criteria, hand and/or forearm immersion studies were pooled. Therefore, the abbreviation HFI collectively refers to cooling of any aspect of the lower arm and/or hand in water. In contrast, MSI refers to the immersion of any combination of the torso, pelvis and/or lower body.

To assess the effectiveness of HFI and MSI protocols, $\mathrm{T}_{\mathrm{C}}$ cooling rate $\left({ }^{\circ} \mathrm{C} \mathrm{min}^{-1}\right)$ criteria (Table 1 ) were adapted from [27]. The cooling rate classifications of McDermott et al. [27] were based on time to lower $\mathrm{T}_{\mathrm{c}}$ analogous with exertional heat stroke $\left(42.2^{\circ} \mathrm{C}\right)$ to $\sim 38.9^{\circ} \mathrm{C}$. Cooling rates of $0.079^{\circ} \mathrm{C} \mathrm{min}{ }^{-1}$ or greater were deemed acceptable and $\mathrm{T}_{\mathrm{c}}$ cooling of greater than $0.155{ }^{\circ} \mathrm{C} \mathrm{min}{ }^{-1}$ were recognised as ideal.

This review reports findings from studies that assessed cooling of non-symptomatic individuals in addition to exertional heat stroke sufferers. In some cases, the $\mathrm{T}_{\mathrm{c}}$ prior to the use of active cooling interventions was lower than the target $\mathrm{T}_{\mathrm{c}}$ of $38.9^{\circ} \mathrm{C}$ cited by McDermott et al. [27]. To ensure firefighters do not exceed the upper

Table 1 Rate of core temperature cooling in individuals from 42.2 to $\sim 38.9^{\circ} \mathrm{C}$

\begin{tabular}{ll}
\hline Cooling category & $\mathbf{T}_{\mathbf{c}}$ cooling rate \\
\hline Ideal (<20 min) & $>0.155^{\circ} \mathrm{C} \mathrm{min}^{-1}$ \\
Acceptable $(20-40 \mathrm{~min})$ & $0.079-0.154^{\circ} \mathrm{C} \mathrm{\textrm {min } ^ { - 1 }}$ \\
Unacceptable $(>40 \mathrm{~min})$ & $<0.078{ }^{\circ} \mathrm{C} \mathrm{min}^{-1}$ \\
\hline
\end{tabular}

Cooling categories represent desired time for cooling [27] 
working $\mathrm{T}_{c}$ limit of $39.0{ }^{\circ} \mathrm{C}$ [23], we proposed that $\mathrm{T}_{c}$ up to $38.0{ }^{\circ} \mathrm{C}$ prior to fire scene re-entry be considered appropriate in healthy, medically monitored and heat acclimatised firefighters. With an anticipated maximal rehabilitation time of $20 \mathrm{~min}$, adjustments to the cooling rates of McDermott et al. [27] to improve specificity for firefighter settings are detailed by (Table 2). Modalities conferring $\mathrm{T}_{\mathrm{c}}$ cooling rates of less than $0.07{ }^{\circ} \mathrm{C} \mathrm{min}{ }^{-1}$, exclusive of afterdrop are likely to require durations beyond $15 \mathrm{~min}$, providing insufficient cooling of firefighters prior to their re-entry to fire scene or delaying their redeployment.

The following descriptive statistics were reported for studies meeting the inclusion criteria; ambient temperature, water temperature, immersion duration, immersion depth, pre-treatment $\mathrm{T}_{\mathrm{c}}$, and $\mathrm{T}_{\mathrm{c}}$ cooling rate $\left({ }^{\circ} \mathrm{C} \mathrm{min}^{-1}\right)$. Reported height and mass measurements in each study were used to calculate body mass index (BMI) [28] and body surface area (BSA) [29].

\section{Results}

Included studies

This review identified 43 treatments utilising MSI (Table 2) and 12 HFI treatments that met the inclusion criteria. Measurement of $T_{c}$ was from the rectum or gastrointestinal tract and research was predominantly conducted in laboratories, with 11 treatments applied in field settings $[2,3,5,20,21,30-34]$. Participants included firefighters, athletes and individuals presenting with exertional heat stroke or exhaustion in emergency medical settings. Water temperatures between 10 and $24.9^{\circ} \mathrm{C}$ were utilised for HFI and participants had similar pretreatment $\mathrm{T}_{\mathrm{c}}\left(38.2-39.0{ }^{\circ} \mathrm{C}\right)$ and immersion durations (10-30 min). Conversely, the MSI studies were more heterogeneous in terms of water temperature $\left(1-26{ }^{\circ} \mathrm{C}\right)$, immersion time (5-42 min), BSA immersed and mean pre-treatment $\mathrm{T}_{\mathrm{c}}\left(38.2-41.7{ }^{\circ} \mathrm{C}\right)$. Immersions generally commenced within $5 \mathrm{~min}$ of exercise cessation.

The rate of $\mathrm{T}_{\mathrm{c}}$ cooling for MSI ranged from $\sim 0.01$ to $0.35{ }^{\circ} \mathrm{C} \mathrm{min}^{-1}$ (Table 3) and were generally considered to be ideal $(\mathrm{n}=23)$ or acceptable $(\mathrm{n}=8)$. Conversely, $\mathrm{T}_{\mathrm{c}}$ cooling rates mediated by HFI ranged from $\sim 0.01$ to $\sim 0.05{ }^{\circ} \mathrm{C} \mathrm{min}^{-1}$ (Table 3), with all HFI and $12 \mathrm{MSI}$ treatments resulting in unacceptable $\mathrm{T}_{\mathrm{c}}$ cooling rates.

Table 2 Proposed rates of cooling for firefighting operations to allow for the rapid safe re-entry of firefighters to emergency incidents

\begin{tabular}{ll}
\hline Classification & $\mathbf{T}_{\mathbf{c}}$ cooling rate \\
\hline Ideal (<10 min) & $>0.10^{\circ} \mathrm{C} \mathrm{min}^{-1}$ \\
Acceptable $(10-15 \mathrm{~min})$ & $0.07-0.10^{\circ} \mathrm{C} \mathrm{min}^{-1}$ \\
Unacceptable $(>15 \mathrm{~min})$ & $<0.07^{\circ} \mathrm{C} \mathrm{\textrm {min } ^ { - 1 }}$ \\
\hline
\end{tabular}

\section{Ideal $\mathrm{T}_{\mathrm{c}}$ cooling rates}

The highest $\mathrm{T}_{\mathrm{c}}$ cooling rate of $0.35{ }^{\circ} \mathrm{C} \mathrm{min}-1$ was reported when participants immersed $\sim 93 \%$ of their body surface area in circulated $2{ }^{\circ} \mathrm{C}$ water [50]. Water temperature was a factor in the effectiveness of the cooling protocols employed. Specifically, water immersion at $2{ }^{\circ} \mathrm{C}$ resulted in superior $\mathrm{T}_{\mathrm{c}}$ cooling rates compared with $8{ }^{\circ} \mathrm{C}\left(0.19{ }^{\circ} \mathrm{C} \mathrm{min}^{-1}\right), 14{ }^{\circ} \mathrm{C}\left(0.15{ }^{\circ} \mathrm{C} \mathrm{min}{ }^{-1}\right)$ and $20{ }^{\circ} \mathrm{C}\left(0.19{ }^{\circ} \mathrm{C} \min ^{-1}\right)$ water. However, all temperatures assessed by Proulx et al. [50] were within the ideal cooling range, and of the 23 treatments producing $T_{c}$ cooling rates deemed to be ideal, Proulx et al. [50] and Lee et al. [48] represented the only treatments utilising a water temperature greater than $14{ }^{\circ} \mathrm{C}$. The 10 treatments that lowered $\mathrm{T}_{\mathrm{c}}$ by a minimum of $0.20{ }^{\circ} \mathrm{C} \mathrm{min}{ }^{-1}$, utilised a water temperature range of 1 to $\sim 10{ }^{\circ} \mathrm{C}$, demonstrating the utility of cold water to rapidly lower $\mathrm{T}_{\mathrm{c}}$. A range of immersion depths resulted in rapid $T_{c}$ cooling. Specifically, ideal $\mathrm{T}_{\mathrm{c}}$ cooling rates were achieved by immersion to depth of mid sternum [34, 41, 48, 51, 53], immersion of the torso without lower body cooling [31], torso and thigh cooling $[32,33,52]$ and 'neck out' immersion in circulated water baths $[47,50,54]$.

To achieve ideal cooling rates, water immersion commenced within $8 \mathrm{~min}$ of exercise cessation with the exception of [51]. The duration of immersion for the ideal cooling rate treatments was generally $12-18 \mathrm{~min}$ [31-34, 41, 47, 49-51] while six treatments were conducted using cooling durations of approximately $10 \mathrm{~min}$ or less $[41,48,50,52,54]$. Pre-treatment $\mathrm{T}_{\mathrm{c}}$ of ideal cooling rate studies were reflective of sustained body heat storage synonymous with a hyperthermic state $\left(\mathrm{T}_{\mathrm{c}}\right.$ $39.5-41.7^{\circ} \mathrm{C}$ ) [31-34, 41, 47-54]. Armstrong et al. [44] reported the highest mean pre-treatment $\mathrm{T}_{\mathrm{c}}$ of $41.7{ }^{\circ} \mathrm{C}$ (individual peak $43.2^{\circ} \mathrm{C}$ ) from a cohort of 14 heat stroke symptomatic athletes. A mean immersion time of $16 \mathrm{~min}$ in $1-3{ }^{\circ} \mathrm{C}$ water returned $\mathrm{T}_{\mathrm{c}}$ to an asymptomatic range,

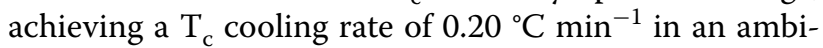
ent temperature of $24.4{ }^{\circ} \mathrm{C}$ [44]. Ambient conditions for the other studies reporting ideal cooling rates were considered temperate to warm $\left(20.0-29.5^{\circ} \mathrm{C}\right)$. With the exception of $[34,41,48,54]$, the participants in the studies reporting ideal cooling rates were classified within the 'normal' BMI range (21.1-24.9 $\mathrm{kg} \mathrm{m}^{-2}$ ).

Overall, ideal $\mathrm{T}_{\mathrm{c}}$ cooling rates were generally achieved by immersion of participants with substantially elevated pre-treatment $\mathrm{T}_{\mathrm{c}}$ for 12-18 $\mathrm{min}$, in water temperatures up to $14^{\circ} \mathrm{C}$.

\section{Acceptable $\mathrm{T}_{\mathrm{c}}$ cooling rates}

Of the eight acceptable treatments, five immersions commenced up to $5 \mathrm{~min}$ following end of exercise protocol. Of the remaining three treatments, immersions were 


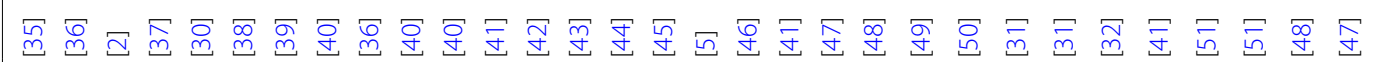

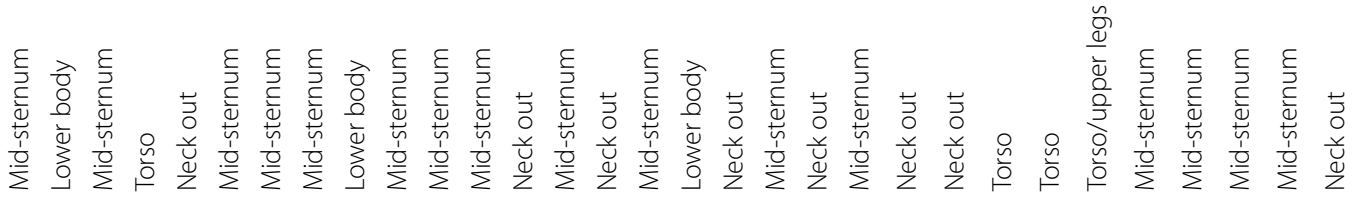

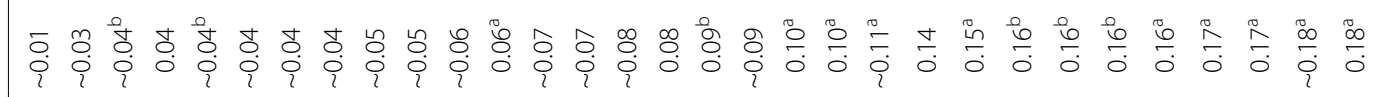

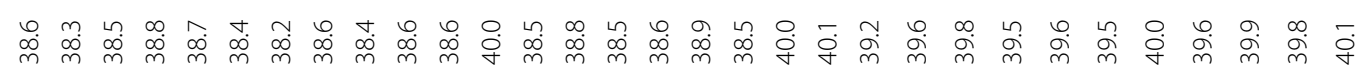

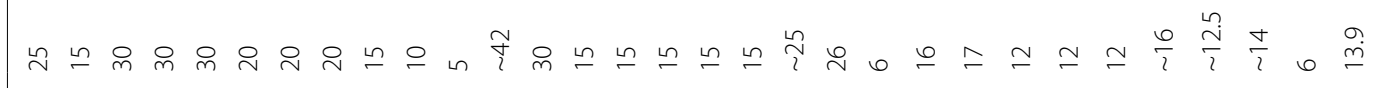

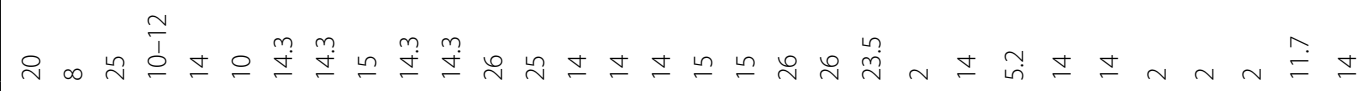

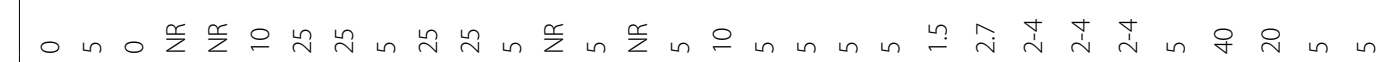

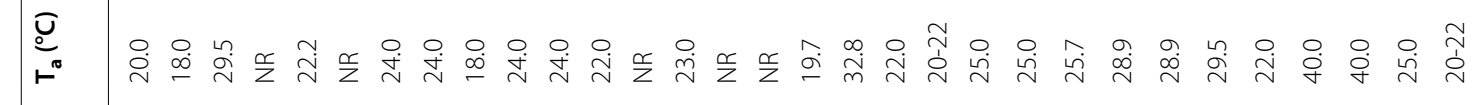

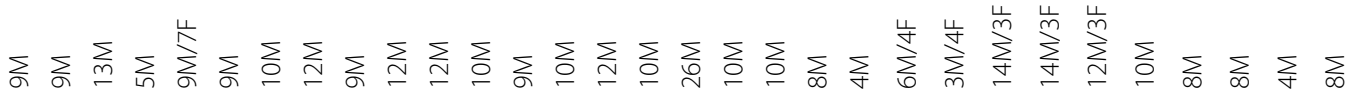




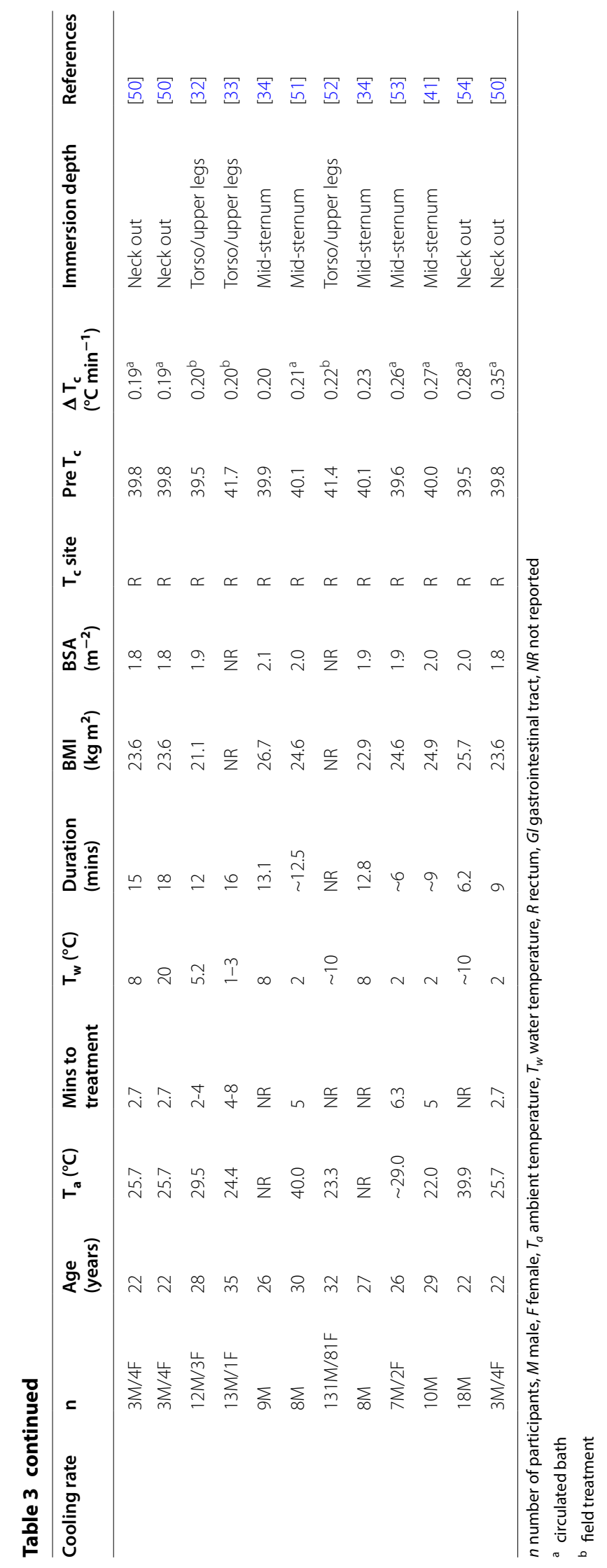


10 min post exercise [5] or not reported [42, 44]. Given a need for firefighters to replenish their equipment and, increasingly engage in decontamination procedures prior to cooling, a delay of up to $10 \mathrm{~min}$ is likely to be seen in firefighting settings. Studies with acceptable $T_{c}$ cooling rates generally employed higher water temperatures than ideal $\mathrm{T}_{\mathrm{c}}$ cooling rate treatments. Five of the eight treatments resulting in acceptable $T_{c}$ cooling rates utilised 14 or $15{ }^{\circ} \mathrm{C}$ water immersion $[5,43-46]$. Three treatments employed temperate water immersion $\left(25-26^{\circ} \mathrm{C}\right)$ to achieve $\mathrm{T}_{\mathrm{c}}$ cooling rates of $\sim 0.07$ to $0.10{ }^{\circ} \mathrm{C} \cdot \mathrm{min}^{-1}$ $[41,42,47]$. Despite similar water temperature $\left(14{ }^{\circ} \mathrm{C}\right)$ and immersion duration (15-17 min), Robey et al. [43] reported a $\mathrm{T}_{\mathrm{c}}$ cooling rate $\left(\sim 0.07{ }^{\circ} \mathrm{C} \mathrm{min}^{-1}\right)$ approximately half that of Proulx et al. [50]. In order to overcome the limiting factor of warmer water temperatures, ideal cooling rates were achieved by circulating water during immersion, with water depth to mid sternum or neck [41, 47].

Studies reporting cooling rates in the acceptable range, generally used immersion to depths of mid sternum or neck [41-47]. Walker et al. [5] was the sole study classified as acceptable that exclusively utilised pelvic and lower body immersion. Immersion duration ranged from 15 to $30 \mathrm{~min}$, with five treatments utilising 15-min immersions [5, 43-46]. Pre-treatment $\mathrm{T}_{\mathrm{c}}\left(38.5-40.1{ }^{\circ} \mathrm{C}\right)$ was generally lower than the ideal $T_{c}$ cooling rate studies. Ambient conditions for studies reporting acceptable cooling rates were considered temperate to hot $\left(19.7-32.8^{\circ} \mathrm{C}\right)$. As for the ideal $\mathrm{T}_{\mathrm{c}}$ cooling rate studies, the acceptable $\mathrm{T}_{\mathrm{c}}$ cooling rate cohorts were classified within the 'normal' BMI range (19.6-24.9 $\mathrm{kg} \mathrm{m}^{-2}$ ), with the exclusion of one cohort $\left(25.8 \mathrm{~kg} \mathrm{~m}^{-2}\right)$ [5].

Overall, studies reporting $T_{c}$ cooling rates in the acceptable range generally utilised immersion to midsternum or neck depth in cool to temperate water $\left(15-26{ }^{\circ} \mathrm{C}\right)$ for participants with pre-treatment $\mathrm{T}_{\mathrm{c}}$ of $38.5-40.1{ }^{\circ} \mathrm{C}$.

\section{Unacceptable $\mathrm{T}_{\mathrm{c}}$ cooling rates}

Twelve MSI and all 12 HFI cooling treatments were classified as delivering unacceptable $\mathrm{T}_{\mathrm{c}}$ cooling rates. With the exception of Hausswirth et al. [35] and Dunne et al. [36], the unacceptable MSI studies yielded $\mathrm{T}_{c}$ cooling rates of $0.04-0.06{ }^{\circ} \mathrm{C} \mathrm{min}^{-1}$. While MSI resulted in

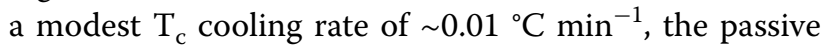
rest condition of Hausswirth et al. [35] resulted in a $\mathrm{T}_{c}$ increase of $\sim 0.7^{\circ} \mathrm{C}$, highlighting residual heat production due to rapid transition from exercise to cooling protocol as a possible confounder. The cooling rate reported by Dunne et al. [36] appears to be a conservative estimate as $\mathrm{T}_{\mathrm{c}}$ decreased a further $\sim 0.8^{\circ} \mathrm{C}$ following cessation of cooling. Excluding Peiffer et al. [40], the MSI studies that resulted in unacceptable cooling rates were characterised by minimum immersion duration of $15 \mathrm{~min}$ [2, 30, 35-41]. Further, $\mathrm{T}_{\mathrm{c}}$ of participants prior to cooling was less than $38.8{ }^{\circ} \mathrm{C}$ for all treatments excluding [41]. Nine of the unacceptable MSI studies employed $8-15{ }^{\circ} \mathrm{C}$ water temperatures, three studies utilised temperate water of $20-26{ }^{\circ} \mathrm{C}[2,35,41]$ and only one of the 12 studies circulated water [41]. A substantial delay ( $25 \mathrm{~min}$ ) between exercise cessation and immersion was reported in four treatments [39, 40].

Ambient temperatures of the MSI studies ranged from 18 to $29.5{ }^{\circ} \mathrm{C}$, whereas six HFI treatments were conducted in $31{ }^{\circ} \mathrm{C}$ or greater $[4,15,20,21]$. In general, the HFI studies (Table 4) were conducted on firefighters who wore t-shirt and open bunker pants while undertaking HFI in reservoirs $[4,15,56-58]$ or commercially available chairs or similar [3, 14, 19-21]. Selkirk et al. [4] was the sole HFI investigation to circulate water. With the exception of pre-treatment $\mathrm{T}_{\mathrm{c}}$ greater than $38.8{ }^{\circ} \mathrm{C}[4$, 58], participants of HFI studies demonstrating unacceptable cooling rates commenced cooling with mean $\mathrm{T}_{\mathrm{c}}$ of $38.2-38.5{ }^{\circ} \mathrm{C}$. Thus, HFI pre-treatment $\mathrm{T}_{\mathrm{c}}$ was generally lower than for those studies resulting in acceptable or ideal cooling rates, but similar to the unacceptable MSI treatments. Excluding Khomenok et al. [57], a minimum of $15 \mathrm{~min}$ HFI was undertaken. Water temperatures for HFI were broadly classified as $10-15{ }^{\circ} \mathrm{C}[19,20,56-58]$ or $\sim 17$ to $24.9^{\circ} \mathrm{C}[3,4,14,15,21,55]$.

Whereas four of the respective ideal and acceptable cooling rate treatments tested participants with mean BMI greater than $25.0 \mathrm{~kg} \mathrm{~m}^{-2}$, a total of 10 cohorts from the unacceptable (seven HFI; three MSI) treatments exceeded this benchmark.

In general, MSI of participants with pre-treatment $\mathrm{T}_{\mathrm{c}}$ of $38.2-38.8{ }^{\circ} \mathrm{C}$ in uncirculated $8-26{ }^{\circ} \mathrm{C}$ water for a minimum $15 \mathrm{~min}$, and all HFI studies resulted in unacceptable cooling rates, respectively.

\section{Discussion}

Rapidly dissipating body heat during rest periods is essential to maximising the safety and operational performance of firefighters, and to maintain the capability of fire services to sustain emergency responses. Yet the most practically efficient method of lowering firefighters $T_{c}$ in field settings remains unresolved. The NFPA recommendation of HFI as an active cooling modality [22] preceded its implementation by fire services in North America, South East Asia and Australia. The unacceptable $\mathrm{T}_{\mathrm{c}}$ cooling rates reported in this review prompt re-evaluation of HFI as a cooling method capable of rapidly lowering firefighters $\mathrm{T}_{\mathrm{c}}$. The cooling protocols deemed acceptable or ideal by this report exclusively utilised immersion of larger body segments, thereby highlighting the potential 
Table 4 Descriptive data for HFI studies meeting the inclusion criteria

\begin{tabular}{|c|c|c|c|c|c|c|c|c|c|c|c|c|}
\hline $\begin{array}{l}\text { Cooling } \\
\text { rate }\end{array}$ & $\mathrm{n}$ & $\begin{array}{l}\text { Age } \\
\text { (years) }\end{array}$ & $\mathrm{T}_{\mathrm{a}}\left({ }^{\circ} \mathrm{C}\right)$ & $\begin{array}{l}\text { Mins } \\
\text { to treat- } \\
\text { ment }\end{array}$ & $\mathrm{T}_{\mathrm{w}}\left({ }^{\circ} \mathrm{C}\right)$ & $\begin{array}{l}\text { Duration } \\
\text { (mins) }\end{array}$ & $\begin{array}{l}\text { BMI } \\
\left(\mathrm{kg} \mathrm{m}^{2}\right)\end{array}$ & $\begin{array}{l}\text { BSA } \\
\left(\mathrm{m}^{-2}\right)\end{array}$ & $\mathrm{T}_{\mathrm{c}}$ site & Pre $T_{c}$ & $\begin{array}{l}\Delta \mathrm{T}_{\mathrm{c}} \\
\left({ }^{\circ} \mathrm{C} \min ^{-1}\right)\end{array}$ & References \\
\hline \multirow{12}{*}{$\begin{array}{l}\text { Unaccep- } \\
\text { table }\end{array}$} & 7NR & 40.0 & 18.0 & NR & 19.0 & 15 & 28.2 & 2.1 & Gl & 38.2 & $\sim 0.01$ & {$[14]$} \\
\hline & $10 \mathrm{M}$ & 22.6 & $N R$ & 5 & 17.0 & 20 & 27.4 & 2.1 & $\mathrm{R}$ & 38.5 & $\sim 0.02$ & {$[55]$} \\
\hline & $15 \mathrm{M}$ & 40.7 & 35.0 & 5 & 17.4 & 20 & 26.5 & 2.1 & $\mathrm{R}$ & 38.3 & $\sim 0.02^{a}$ & {$[4]$} \\
\hline & $9 \mathrm{M}$ & 22.0 & 31.2 & 3 & $16.4-17.8$ & 30 & 21.5 & 1.9 & $\mathrm{R}$ & 38.5 & $\sim 0.02$ & {$[15]$} \\
\hline & $24 \mathrm{M} / 1 \mathrm{~F}$ & 36.5 & 32.5 & 0 & $\sim 10.0$ & 15 & 25.6 & 2.0 & Gl & 38.2 & $\sim 0.03^{b}$ & {$[20]$} \\
\hline & $6 \mathrm{M}$ & $N R$ & 35.0 & 5 & 17.4 & 20 & $N R$ & $N R$ & $\mathrm{R}$ & 38.9 & $\sim 0.03^{\mathrm{a}}$ & {$[4]$} \\
\hline & $14 N R$ & 29.3 & 15.0 & NR & 12.5 & 20 & $N R$ & $N R$ & Gl & 38.5 & $\sim 0.04$ & {$[56]$} \\
\hline & $17 \mathrm{M}$ & 24.0 & 35.0 & 0 & 10.0 & 10 & 21.7 & 1.8 & $\mathrm{R}$ & $\sim 38.2$ & $\sim 0.04$ & {$[57]$} \\
\hline & $10 \mathrm{M} / 2 \mathrm{~F}$ & 30.7 & $33.3-36.9$ & 0 & 24.9 & 20 & 26.4 & 2.0 & Gl & 38.5 & $0.05^{b}$ & {$[21]$} \\
\hline & $11 \mathrm{NR}$ & 32.2 & 22.5 & NR & 20.9 & 30 & 28.2 & 2.0 & Gl & 38.3 & $0.05^{b}$ & [3] \\
\hline & $14 \mathrm{M} / 4 \mathrm{~F}$ & 25.9 & 24.0 & NR & 14.3 & 20 & 25.5 & 1.9 & Gl & $\sim 38.3$ & $\sim 0.05$ & [19] \\
\hline & $6 \mathrm{M} / 1 \mathrm{~F}$ & 25.0 & 20.7 & $N R$ & 12.0 & 15 & 23.9 & 1.9 & $R$ & 39.0 & $\sim 0.05$ & [58] \\
\hline
\end{tabular}

$n$ number of participants, $M$ male, $F$ female, $T_{a}$ ambient temperature, $T_{w}$ water temperature, $R$ rectum, $G /$ gastrointestinal tract, $N R$ not reported

a circulated bath

b field treatment

of MSI to rapidly lower $\mathrm{T}_{\mathrm{c}}$ of firefighters following work tasks in the heat. The following sections discuss factors contributing to the efficacy of water based cooling, inclusive of cooling thermodynamics, BSA cooled, duration of cooling, pre-treatment $T_{c}$, and the effect of environmental conditions. Practical considerations for the use of water based cooling of firefighters at the fire-scene are also discussed to yield practical evidenced based guidelines.

\section{Afterdrop}

Prior to considering the implications of the review findings for fire scene rehabilitation, the physiology of water immersion must be considered. The critical analysis of the literature is complicated by $\mathrm{T}_{\mathrm{c}}$ measurement immediately following immersion, where steep thermal gradients may exist within the body. As a consequence, such data may not account for the 'afterdrop' phenomenon, where the redistribution of body heat to cooled tissues post-immersion results in a rapid $\mathrm{T}_{\mathrm{c}}$ decline. The afterdrop occurs due to counter current (blood to blood), convective (blood to tissue) and conductive (tissue to tissue) mechanisms [59], and is therefore proportional to cooling 'stimulus' (water temperature, duration and body surface area cooled). Hence, the afterdrop phenomenon has greater relevance for MSI studies, with cooling rates reported immediately post immersion likely representing conservative estimates of $T_{c}$ cooling where the afterdrop was not accounted for. For example, Dunne et al. [36] utilised 15 min of lower body immersion in $15{ }^{\circ} \mathrm{C}$ to reduce mean $\mathrm{T}_{\mathrm{c}}$ by $\sim 0.5{ }^{\circ} \mathrm{C}$ during cooling, and reported a further mean $\mathrm{T}_{\mathrm{c}}$ decrease of $\sim 0.8^{\circ} \mathrm{C}$ from cessation of cooling to the 5th min of subsequent exercise bout. Hence, less than half the total $\mathrm{T}_{\mathrm{c}}$ decrease occurred during immersion, and the total cooling power was therefore not reflected in the reported cooling rate of $\sim 0.03^{\circ} \mathrm{C} \mathrm{min}{ }^{-1}$.

\section{Body surface area cooled}

It is intuitive to expect a relationship between the proportion of body surface immersed and $\mathrm{T}_{\mathrm{c}}$ cooling rates. With the exception of one study [30], 'neck out' immersion resulted in $\mathrm{T}_{\mathrm{c}}$ cooling rates $\left(0.08-0.35{ }^{\circ} \mathrm{C} \mathrm{min}{ }^{-1}\right)$ that were deemed acceptable or ideal [44, 46, 47, 49, 50]. Should these results be replicated at fire scenes, cooling firefighters from $\mathrm{T}_{\mathrm{c}}$ of $39.0^{\circ} \mathrm{C}$ to a desirable fire scene re-entry $\mathrm{T}_{c}$ of less than $38.0{ }^{\circ} \mathrm{C}$ would require $\sim 3$ to $\sim 13 \mathrm{~min}$. Based upon this analysis, the most effective depth of immersion for returning firefighters to safe $T_{c}$ limits [22, 23] is likely to be 'neck out' cooling.

While firefighter rehabilitation should aim to rapidly reduce $T_{c}$ prior to redeployment, the use of cold water immersion on large surface areas may not be well tolerated, and little is known of firefighters ability to return to work in these scenarios. In laboratory settings, the impact of MSI on subsequent physical performance is dependent upon the extent of $\mathrm{T}_{\mathrm{c}}$ and muscular cooling, and work activities undertaken. Endurance performances generally improve due to reduced $\mathrm{T}_{\mathrm{c}}[32,45]$, while high velocity movements exhibit the greatest performance susceptibility to lower muscle temperatures [39, 60]. Acknowledging the reduction of muscle temperature with cold water immersion, Versey et al. [61] recommend that athletes allow a minimum of $45 \mathrm{~min}$ from cessation of immersion 
to performance of high intensity, explosive activities unless an adequate warm up is undertaken. Such a delay is not tenable during an emergency response. While firefighters may be required to undertake some high intensity tasks [62], they are not likely to replicate the demands of elite sport, and are anticipated to commence muscular rewarming through metabolic heat production, muscular perfusion and insulation of skin upon re-application of PPC [63]. Post immersion issues were not reported for firefighters returning to work following two $30 \mathrm{~min}$ bouts of temperate water immersion to mid sternum despite lowering mean $\mathrm{T}_{\mathrm{c}}$ below resting values during the subsequent work phase [2]. If low muscle temperature was identified as limiting firefighter physical performance, exclusively cooling the torso ( $35 \% \mathrm{BSA}$ ) by recumbent cool water immersion $\left(10-14{ }^{\circ} \mathrm{C}\right)$ in a small pool or tub is an alternative that has achieved equivocal results [31,37]. While additional analysis of this technique is required, such an approach has been used in elite sport settings during brief (10 min) scheduled breaks in play to simultaneously remove body heat and minimise muscle temperature decrement of the lower body [24].

A compromise between 'neck out' and torso only immersion is the combination of torso and upper leg cooling (54 \% BSA). Three treatments utilised this approach in $1-14{ }^{\circ} \mathrm{C}$ water to achieve ideal $\mathrm{T}_{\mathrm{c}}$ cooling rates $\left(0.16-0.20{ }^{\circ} \mathrm{C} \mathrm{min}-1\right)[32,33]$. The efficacy of this method with temperate water is yet to be reported, however it's not expected to achieve ideal $\mathrm{T}_{\mathrm{c}}$ cooling rates. The most commonly applied water depth of studies in this review was immersion to the mid sternum, with mixed results $\left(0.01-0.27{ }^{\circ} \mathrm{C} \mathrm{min}^{-1}\right)$. Ideal and acceptable $\mathrm{T}_{\mathrm{c}}$ cooling rates for mid sternum depth immersion were achieved across a broad range of water temperatures $\left(2-23.5^{\circ} \mathrm{C}\right)$, and $\mathrm{T}_{\mathrm{c}}$ cooling rates were 0.10 to $\sim 0.18{ }^{\circ} \mathrm{C} \mathrm{min}^{-1}$ when water was circulated. An example of the cooling power conferred by water circulation is presented by a comparison of Gagnon et al. [49] and Proulx et al. [50]. Gagnon et al. [49] reported a cooling rate of $0.14{ }^{\circ} \mathrm{C} \mathrm{min}^{-1}$, which is less than half the rate achieved by Proulx et al. [50] for comparable water temperature, pre-treatment $T_{c}$ and immersion depth. Unlike Gagnon et al. [49], Proulx et al. [50], circulated water, thereby minimising warming of the boundary layer to maintain the thermal gradient between water and the skin. Thus, where feasible, it is recommended to circulate water during immersions to minimise the required immersion duration. Water circulation is likely to be of greater importance during temperate water immersion, where narrower water to skin gradients extend the required cooling times.

In contrast to 'neck out', mid sternum, and torso immersion, HFI relies on cooling applied to a combined body surface area of just $19 \%$. Yet this small biological mass is thought to be preferential for heat exchange with NFPA 1584 stating "the vascularity of blood vessels close to the skin of the arms and hands acts as an excellent means of heat transfer" [22]. The existence of arteriovenous anastomoses (AVA) are cited within the HFI literature $[4,14,19]$ as the rationale for preferential heat transfer. Return of blood flow from the extremities through superficial veins of the forearms is thought to permit superior heat exchange during cooling, due to the higher rate of blood flow compared with the capillaries [64]. Additionally, Taylor et al. [65] highlight the superior surface area to mass ratio of the hands as a complimentary factor supporting heat loss. Yet, it's apparent from studies examined in this review, that regardless of the perceived advantages presented by AVA's, HFI lacks cooling power given the unacceptable $\mathrm{T}_{\mathrm{c}}$ cooling rates to date.

Like the hands and forearms, the shallow arteries of the neck, groin and axilla regions ought to provide for preferential heat exchange. Ice pack cooling of these regions is currently recommended by the Australian Resuscitation Council for heat stroke symptomatic patients [66]. However, as for HFI, cooling of these regions by instant cold packs also produce unacceptable $\mathrm{T}_{\mathrm{c}}$ cooling rates [67], that can be improved to $0.07{ }^{\circ} \mathrm{C} \mathrm{min}^{-1}$ through extended application (40 min) of larger ice volumes [68]. Collectively, these reports highlight that brief localised superficial cooling is unlikely to achieve acceptable $T_{c}$ cooling rates in firefighting settings. Use of water less than $10{ }^{\circ} \mathrm{C}$ may improve HFI cooling rates, but is likely to negatively impact manual dexterity following immersions of just 5 min [69]. Further, the logistical issues surrounding the provision of cold water, particularly in tropical settings, will minimise the likelihood of adoption by fire services.

\section{Pre-treatment $T_{c}$ and duration of cooling}

Cooling at fire scenes must occur rapidly to allow firefighters to safely re-enter fire affected buildings or redeployment to other operational tasks. Thus employing cooling methods that minimise the required exposure time are of interest to incident controllers and fire services generally. Immersion duration should be considered with $\mathrm{T}_{\mathrm{c}}$ prior to cooling, as a fivefold increase in duration can produce a threefold decrease in cooling rate [48]. Specifically, where cooling commences at a relatively low $\mathrm{T}_{\mathrm{c}}$ post work, cooling rates are likely to be lower than those where $\mathrm{T}_{\mathrm{c}}$ approaches $40{ }^{\circ} \mathrm{C}$. With a minimum pretreatment $\mathrm{T}_{\mathrm{c}}$ of $39.5{ }^{\circ} \mathrm{C}$, treatments classified as ideal established a larger temperature gradient between deep tissue and water than all but two of the acceptable, and two of the unacceptable MSI studies, respectively. Thus, it appears that MSI is likely to be most effective when $T_{c}$ 
is high and time critical cooling is necessary. An interesting observation of HFI research is that $\mathrm{T}_{\mathrm{c}}$ prior to cooling has exceeded $38.5{ }^{\circ} \mathrm{C}$ on just two occasions $[4,58]$. Low pre-treatment $\mathrm{T}_{\mathrm{c}}\left(38.2-38.5{ }^{\circ} \mathrm{C}\right)$ also confounded MSI with cooling rates of $\sim 0.03$ to $\sim 0.09{ }^{\circ} \mathrm{C} \mathrm{min}^{-1}[2,36,38$, $39,42,44,46]$, that were generally lower compared with treatments where higher $T_{c}$ was prevalent. Thus, the unacceptable $T_{c}$ cooling rates for HFI could be partially attributed to this observation, as higher $T_{c}$ appears to provide a preferential gradient for heat exchange. Examination of HFI treatments applied to cohorts with higher pre-treatment $\mathrm{T}_{\mathrm{c}}$ is warranted.

The unacceptable cooling treatments were applied to a greater proportion of cohorts with BMI in the overweight or obese categories $\left(>25.0 \mathrm{~kg} \mathrm{~m}^{-2}\right)$, than those studies reporting ideal and acceptable cooling rates. Higher body mass [70] and lean body mass [41] slow $\mathrm{T}_{\mathrm{c}}$ cooling rate, requiring colder water and/or extended immersion duration to increase heat transfer. This is an important consideration when implementing fireground cooling, as BMI is likely to be above the normal range [71-73] due, in part to increased muscle mass required to safely complete firefighting tasks. The aforementioned circulation of water during immersion may offset some of the additional immersion time required for high BMI cohorts. Firefighter age and gender are additional considerations for determining optimal cooling strategies. Ageing is associated with deteriorating body composition of firefighters [73], and older individuals demonstrate decreased ability to dissipate body heat during and following physical activity $[74,75]$. Disparities in body composition also contribute to gender differences for body heat dissipation [76], potentially placing female firefighters at a thermoregulatory disadvantage to male counterparts. The ageing firefighter workforce [73] and the push to increase the proportion of female firefighters working in urban fire services worldwide [77], highlight the need to expand MSI and HFI research beyond the predominantly young male cohorts examined to date.

Irrespective of firefighter characteristics, effective cooling during rest breaks should manifest in lower $T_{c}$ than achieved by resting in the shade. A lower $T_{c}$ upon fire scene re-entry is likely to permit maintenance of cooler $\mathrm{T}_{\mathrm{c}}$ during a standardised workload, however this has been infrequently assessed. While this review included 43 MSI treatments, the effect of only seven treatments were evaluated during a subsequent work bout. Each MSI treatment resulted in a lower pre and post exercise $T_{c}$ than control trial during fixed and self paced exercise of 6-45 min [2, 32, 35, 36, 42, 45, 46]. In contrast, five HFI treatments examined a subsequent work bout with indifferent results. Where HFI lowered $T_{c}$ to a greater extent than control trial, a lower $\mathrm{T}_{\mathrm{c}}$ was maintained throughout the exercise period (20-60 $\mathrm{min})[4,14,57]$, albeit to a lesser degree than the MSI treatments. Conversely, Hostler et al. [19] and Zhang et al. [58] failed to lower $T_{c}$ with reference to their respective control groups and reported no $T_{c}$ differences during the following work bout. While additional cooling studies mimicking fireground rehabilitation are required, the $T_{c}$ benefits of MSI prior to subsequent exercise appear to be maintained throughout protocols tested to date.

\section{Environmental conditions}

While highlighting the inability of HFI to lower $T_{c}$ to pre-work levels, and that the highest $\mathrm{T}_{\mathrm{c}}$ cooling rates had been achieved with reservoirs larger than those provided by commercially available chairs, McEntire et al. [78] declared "HFI is likely the best modality for cooling firefighters in hot, humid conditions". Hot and humid conditions present a unique challenge for firefighter welfare, by combining the greatest need for cooling with challenging conditions to administer it. Yet, when tested in ambient temperatures exceeding $28{ }^{\circ} \mathrm{C}$, HFI in water temperatures of $10-24.9^{\circ} \mathrm{C}$ resulted in $\mathrm{T}_{\mathrm{c}}$ cooling rates of $0.02-$ $0.04{ }^{\circ} \mathrm{C} \min ^{-1}[4,15,21,57,58]$. The relatively slow $\mathrm{T}_{\mathrm{c}}$ cooling rates reported by these studies, ought to prompt investigation of alternate cooling strategies for time sensitive operations in the heat. By excluding research that did not use thermal or chemical protective clothing during exertion from their analysis, McEntire et al. [78] omitted all 43 MSI treatments reported by the current review, despite recognition of MSI as a valid cooling method for use with heat affected individuals [79]. When MSI was conducted in similar ambient temperatures $\left(>28^{\circ} \mathrm{C}\right)$ and utilised comparable water temperatures $\left(\sim 10-25{ }^{\circ} \mathrm{C}\right)$ to the aforementioned HFI studies, superior $\mathrm{T}_{\mathrm{c}}$ cooling rates $\left(\sim 0.04\right.$ to $\left.0.28{ }^{\circ} \mathrm{C} \mathrm{min}^{-1}\right)$ were reported $[2,31,32$, $46,54]$. Thus, it is likely that immersion of larger proportions of BSA will minimise the influence of adverse environmental conditions on $\mathrm{T}_{\mathrm{c}}$ cooling rates, as water is a superior conductor of energy than air [80], clamping skin temperature near that of the water.

In hot operating environments, cold water provision may be a logistical issue, prompting the analysis of temperate water immersion as provided by reticulated supplies. In a tropical setting, Brearley et al. [2] reported that mid sternum depth MSI in $25{ }^{\circ} \mathrm{C}$ water produced $\mathrm{T}_{\mathrm{c}}$ cooling rates of $\sim 0.05{ }^{\circ} \mathrm{C} \mathrm{min}^{-1}$ over $15 \mathrm{~min}$, and $\sim 0.04{ }^{\circ} \mathrm{C} \mathrm{min}^{-1}$ over $30 \mathrm{~min}$. Despite the relatively slow cooling rates, MSI resulted in an afterdrop during the initial $10 \mathrm{~min}$ of a second work bout post-cooling. Modifying the cooling protocol to increase immersion depth and/or circulating water [81] is likely to facilitate more rapid cooling. This was demonstrated by Taylor et al. [47], who achieved a cooling rate of $0.10{ }^{\circ} \mathrm{C} \mathrm{min}^{-1}$ 
for 'neck out' immersion in circulated $26^{\circ} \mathrm{C}$ water. Additional support for temperate MSI is provided by the acceptable [41, 42] and ideal [48] cooling rates. Thus, on available evidence, temperate MSI confers greater cooling than HFI and is therefore better suited for use by firefighters working in hot and humid conditions.

Based on the $\mathrm{T}_{c}$ cooling rates reported by this review, protracted rehabilitation times are anticipated when utilising HFI for post incident cooling. Specifically, utilising the highest cooling rate reported for HFI of $\sim 0.05{ }^{\circ} \mathrm{C} \min ^{-1}$ [19], achieving $\mathrm{T}_{\mathrm{c}}$ reduction from $39.0{ }^{\circ} \mathrm{C}$ to less than $38.0{ }^{\circ} \mathrm{C}$ within the 20 min recovery period is unlikely ( 19 min), particularly when allowing for reconditioning of breathing apparatus and PPC prior to fire scene re-entry. It is possible that higher $\mathrm{T}_{\mathrm{c}}$ prior to HFI would produce more rapid cooling rates than those reported within this review. However, the setting in which HFI yielded a cooling rate of $\sim 0.05^{\circ} \mathrm{C} \mathrm{min}^{-1}$, found no benefit for HFI compared to passive rest in temperate conditions $\left(24{ }^{\circ} \mathrm{C}\right)$, use of a hand cooling device, infusion of $4{ }^{\circ} \mathrm{C}$ intravenous fluids, fan cooling, or ice vests. In that study, only two of 17 participants (including 13 firefighters) rated HFI as the method that 'reduced their temperature the most' [19]. Furthermore, HFI was not rated as the cooling method 'that felt best' by any participant, and no participant rated HFI as 'first choice of cooling on the fireground' [19]. Such perceptions may contribute to the apparent infrequent use of forearm cooling chairs, despite their availability within USA fire services [20].

\section{Logistical considerations}

Cheung et al. [82] acknowledge the cooling benefits of MSI. However, they conclude, "the logistical difficulties involved with erecting multiple baths and supplying cold water in the field, along with the need to remove and don equipment, limit the feasibility of this technique". A key factor in the comparison of HFI and MSI is that both techniques require the provision of water to establish reservoirs for cooling. As demonstrated by DeGroot et al. [83] in a military setting, establishing group HFI is comparable to preparing small baths, whereas individual HFI requires discrete buckets or chairs with reservoirs for each arm. Thus, given that both methods require a similar 'footprint' at the fire scene and also dedicated rehabilitation staff to monitor and maintain cooling apparatus, there are negligible differences in the logistics of water provision for MSI or HFI.

A benefit of firefighter HFI is the time advantage of not removing boots and pants prior to cooling, permitting additional cooling time during rest periods (estimated at 2-3 min). Yet, wearing PPC during rehabilitation likely slows the rate of cooling during rest periods, and this may contribute to the unacceptable HFI cooling rates.
Furthermore, the superior $\mathrm{T}_{\mathrm{c}}$ cooling rates reported for MSI indicate that any time benefits of only partially removing PPC would likely be overcompensated for by the disparity in time to cool the body. While MSI during brief rest periods may be viewed as time inefficient, implementation of MSI during short scheduled breaks of elite individual [84] and team sport competition [24], highlights the utility of this method in time sensitive field settings.

Establishing firefighter cooling would be expedited by deployment of a purpose built rehabilitation facility to fire scenes. Several recommended schematics exist [2, 22] that permit firefighter rehabilitation in a discrete setting, isolated from public view. Public perception is an important consideration when establishing a fireground rehabilitation sector, as firefighters undertaking HFI or MSI in public view while colleagues are responding to an emergency may be misinterpreted as an inadequate response. Screened sides/walls of the rehabilitation sector or a transportable pod [5] would allow for privacy and negate concerns of inferior public image due to firefighters undertaking cooling. Conversely, visibly compromised firefighters re-entering the fire scene could undermine public confidence.

\section{Limitations of this review}

This review applied the criterion of $\mathrm{T}_{\mathrm{c}}$ cooling rate to evaluate the efficacy of MSI and HFI treatments following physical exertion, excluding additional physiological variables and perceptual ratings from the analysis. The lack of research systematically contrasting MSI and HFI treatments of the same cohort is a limitation of this field of research and therefore this review. Furthermore, the heterogeneous nature of the MSI research compared to HFI in terms of pre-treatment $T_{c}$ and water temperature, provides a more comprehensive overview of the responses to MSI than HFI. Lastly, there is limited data regarding implementation of MSI and HFI in firefighting settings, with particular reference to performing physical activity post cooling.

\section{Recommendations for future research}

Crossover design studies controlling for heat acclimatisation status, fitness and experience are recommended to evaluate the responses of emergency responders to HFI and MSI. Studying the responses to MSI and HFI of cohorts with varied age categories, inclusive of female participants, would more accurately reflect modern firefighting populations. Evaluation criteria should include well-being and productivity measures in addition to $\mathrm{T}_{\mathrm{c}}$ cooling rate. Pre-treatment $\mathrm{T}_{\mathrm{c}}$ should represent substantially elevated $\mathrm{T}_{\mathrm{c}}\left(\sim 39.5{ }^{\circ} \mathrm{C}\right)$ beyond the narrow range currently tested within HFI research, while conforming 
to ethical guidelines. The $\mathrm{T}_{c}$ afterdrop following HFI and MSI ought to be accounted for during such research, and inclusion of functional movement variables would be beneficial.

\section{Summary}

There are examples of HFI indoctrinated within North American fire department policies and recent examples from Australasia. The adoption of HFI for firefighter rehabilitation seems to be underpinned by the NFPA 1584 recommendation of HFI as an active cooling modality [22], referencing an investigation examining just two cooling interventions, HFI in $17.4{ }^{\circ} \mathrm{C}$ water, and seated rest in front of a misting fan compared to a passive control [4]. While HFI was more effective than seated rest in lowering $\mathrm{T}_{\mathrm{c}}$, the cooling rate was modest $\left(0.02{ }^{\circ} \mathrm{C} \mathrm{min}-1\right)$, and not evaluated against proven field based cooling methods.

Despite the use of MSI in similarly time sensitive and high pressure environments to those faced by firefighters, including elite sport and medical settings, MSI remains largely untested in firefighter rehabilitation settings. This is a surprising outcome given that MSI in cold water has been recognised as the gold standard for treatment of exertional heatstroke and restoration of function for heat affected individuals for the past 115 years [85]. Of the two known studies to employ water immersion in firefighter rehabilitation settings, both have demonstrated the utility of MSI for lowering $T_{c}$ when compared with passive cooling methods. Cold water, lower body immersion for $15 \mathrm{~min}$ in temperate conditions [5] achieved acceptable $T_{c}$ cooling rates, while 30 min of temperate water immersion to a depth of mid sternum in tropical conditions [2] resulted in unacceptable cooling rates by not accounting for an afterdrop. Further, despite the relatively slow cooling rates reported by Brearley et al. [2], MSI achieved twice the $T_{c}$ cooling reported by Selkirk et al. [4] for HFI in harsh environmental conditions. While HFI is yet to be thoroughly evaluated against MSI in hot settings, pilot testing in hot and humid conditions by the authors identified that alternative cooling modalities were more likely to achieve acceptable $\mathrm{T}_{\mathrm{c}}$ cooling rates (unpublished observations).

\section{Conclusions}

Based upon the extensive field of research supporting immersion of large body surface areas and comparable logistics of establishing HFI or MSI, it is recommended that fire and rescue management reassess their approach to fireground rehabilitation of responders. Specifically, we question the use of HFI to rapidly lower firefighter core body temperature during rest periods. By utilising MSI to restore firefighter $\mathrm{T}_{\mathrm{c}}$ to safe working levels, fire and rescue services would adopt an evidence-based approach to maintaining operational capability during arduous, sustained responses. While the optimal MSI protocol will be determined by the specifics of a given response, maximising the body surface area immersed in circulated water of up to $26{ }^{\circ} \mathrm{C}$ for 15 min is likely to return firefighter $T_{c}$ to safe working levels during rest periods. Cooler water temperatures will augment $T_{c}$ cooling rates and minimise immersion duration.

\section{Abbreviations}

AVA: arteriovenous anastomoses; BMI: body mass index; BSA: body surface area; HFI: hand and forearm immersion; MSI: multi segment immersion; NFPA: National fire and protection authority; PPC: protective clothing; $\mathrm{T}_{\mathrm{c}}$ : core body temperature.

\section{Authors' contributions}

$M B$ conceived the idea of the review. The manuscript was written by MB and AW. Both authors read and approved the final manuscript.

\section{Author details}

${ }^{1}$ National Critical Care and Trauma Response Centre, Level 8 Royal Darwin Hospital, Rocklands Drive, Tiwi, NT 0810, Australia. ${ }^{2}$ Discipline of Sports Studies, Faculty of Health, UC Research Institute for Sport and Exercise, University of Canberra, Canberra, ACT 2601, Australia. ${ }^{3}$ Australian Capital Territory Fire and Rescue, Amberley Avenue, Fairbairn Business Park, Majura, ACT 2609, Australia.

\section{Compliance with ethical guidelines}

\section{Competing interests}

The authors declare that they have no competing interests.

Received: 27 June 2015 Accepted: 17 September 2015

Published online: 30 September 2015

\section{References}

1. McLellan TM, Cheung SS. Impact of fluid replacement on heat storage while wearing protective clothing. Ergonomics. 2000;43:2020-30.

2. Brearley MB, Norton I, Trewin T, Mitchell C. Fire fighter cooling in tropical field conditions. National Critical Care and Trauma Response Centre. 2011. http://www.nationaltraumacentre.nt.gov.au/what-we-do/our-research/ research-papers. Accessed 16 July 2014. doi:10.13140/RG.2.1.3323.6325.

3. Colburn D, Suyama J, Reis SE, Morley J, Goss F, Chen Y, Moore C, Hostler D. A comparison of cooling techniques in firefighters after a live burn evolution. Prehosp Emerg Care. 2011;15:226-32.

4. Selkirk GA, McLellan TM, Wong J. Active versus passive cooling during work in warm environments while wearing firefighting protective clothing. J Occup Environ Hyg. 2004;1:521-31.

5. Walker A, Driller M, Brearley M, Argus C, Rattray B. Cold Water Immersion and Iced Slush Ingestion are effective at cooling firefighters following a simulated search and rescue task in a hot environment. Appl Physiol Nutr Metab. 2014;39:1159-66.

6. Selkirk GA, McLellan TM. Influence of aerobic fitness and body fatness on tolerance to uncompensable heat stress. J Appl Physiol. 2001;91:2055-63.

7. Tikuisis P, McLellan TM, Selkirk GA. Perceptual versus physiological heat strain during exercise-heat stress. Med Sci Sports Exerc. 2002;34:1454-61.

8. Cheuvront SN, Kenefick RW, Montain SJ, Sawka MN. Mechanisms of aerobic performance impairment with heat stress and dehydration. J Appl Physiol. 2010;109:1989-95.

9. Hancock PA, Ross JM, Szalma JL. A meta-analysis of performance response under thermal stressors. Hum Factors. 2007;49(5):851-77.

10. Hostler D, Suyama J, Guyette FX, Moore CG, Pryor RR, Khorana P, McEntire SJ, Comer D, Reis SE. A randomized controlled trial of aspirin and 
exertional heat stress activation of platelets in firefighters during exertion in thermal protective clothing. Prehosp Emerg Care. 2014;18(3):359-67.

11. Smith DL, Petruzzello SJ, Chludzinski MA, Reed JJ, Woods JA. Selected hormonal and immunological responses to strenuous live-fire firefighting drills. Ergonomics. 2005;48(1):55-65.

12. Walker A, Keene T, Argus C, Driller M, Guy JH, Rattray B. Immune and inflammatory responses of Australian firefighters after repeated exposures to the heat. Ergonomics. 2015;17:1-8.

13. Walker A, Argus C, Driller M, Rattray B. Repeat work bouts increase thermal strain for Australian firefighters working in the heat. Int J Occup Environ Health. 2015. doi:10.1179/2049396715Y.0000000006.

14. Barr D, Reilly T, Gregson W. The impact of different cooling modalities on the physiological responses in firefighters during strenuous work performed in high environmental temperatures. Eur J Appl Physiol. 2011;111:959-67.

15. Barwood MJ, Davey S, House JR, Tipton MJ. Post-exercise cooling techniques in hot, humid conditions. Eur J Appl Physiol. 2009;107:385-96.

16. Kenny GP, Schissler AR, Stapleton J, Piamonte M, Binder K, Lynn A, Lan CQ, Hardcastle SG. Ice cooling vest on tolerance for exercise under uncompensable heat stress. J Occup Environ Hyg. 2011:8:484-91.

17. Espinosa N. Can we stand the heat? J Emerg Serv. 2008;33:94-105.

18. Hostler D, Bednez J, Kerin S, Reis SE, Kong PW, Morley J, Gallagher MJ, Suyama J. Comparison of rehydration regimens for rehabilitation of firefighters performing heavy exercise in thermal protective clothing: a report from the Fireground Rehab Evaluation (FIRE) trial. Prehosp Emerg Care. 2010;14:194-201.

19. Hostler D, Reis SE, Bednez JC, Kerin S, Suyama J. Comparison of active cooling devices with passive cooling for rehabilitation of firefighters performing exercise in thermal protective clothing: a report from the Fireground Rehab Evaluation (FIRE) trial. Prehosp Emerg Care. 2010;14:300-9.

20. Burgess JL, Duncan MD, Hu C, Littau SR, Caseman D, Kurzius-Spencer M, Davis-Gorman G, McDonagh PF. Acute cardiovascular effects of firefighting and active cooling during rehabilitation. J Occup Environ Med. 2012;54(11):1413-20.

21. Savage RJ, Lord C, Larsen BL, Knight TL, Langridge PD, Aisbett B. Firefighter feedback during active cooling: a useful tool for heat stress management? J Therm Biol. 2014;46:65-71.

22. NFPA 1584. Standard on the rehabilitation process for members during emergency operations and training exercises. Qunicy: National Fire Protection Association; 2015.

23. ISO 9886:2004(E). Ergonomics — evaluation of thermal strain by physiological measurements. Geneva: International Organisation for Standardisation; 2004.

24. Brearley M, Saunders P. Heat. In: Tanner RK, Gore CK, editors. Physiological tests for elite athletes. 2nd ed. Champaign: Human Kinetics; 2013. p. 131-47. doi:10.13140/RG.2.1.2449.0080.

25. Keene T, Brearley M, Bowen B, Walker A. Accuracy of tympanic measurement in firefighters completing a simulated structural firefighting task. Prehosp Disaster Med. 2015. doi:10.1017/S1049023X15005038.

26. Hardy JD, DuBois EF, Soderstrom GF. The technic of measuring radiation and convection: one figure. J Nutr. 1938;15:461-75.

27. McDermott BP, Casa DJ, Ganio MS, Yeargin SW, Armstrong LE, Maresh CM. Acute whole-body cooling for exercise-induced hyperthermia: a systematic review. J Athl Train. 2009;44:84-93.

28. Baur DM, Christophi CA, Tsismenakis AJ, Jahnke SA, Kales SN. Weight-perception in male career firefighters and its association with cardiovascular risk factors. BMC Public Health. 2012;12:480.

29. DuBois D, DuBois EF. A formula to estimate the approximate surface area if height and weight be known. Arch Int Med. 1916;17:863-71.

30. DeMartini JK, Ranalli GF, Casa DJ, Lopez RM, Ganio MS, Stearns RL, McDermott BP, Armstrong LE, Maresh CM. Comparison of body cooling methods on physiological and perceptual measures of mildly hyperthermic athletes. J Strength Cond Res. 2011;25(8):2065-74.

31. Clements JM, Casa DJ, Knight J, McClung JM, Blake AS, Meenen PM, Gilmer AM, Caldwell KA. Ice-water immersion and cold-water immersion provide similar cooling rates in runners with exercise-induced hyperthermia. J Athl Train. 2002;37(2):146-50.

32. Yeargin SW, Casa DJ, McClung JM, Knight JC, Healey JC, Goss PJ, Harvard WR, Hipp GR. Body cooling between two bouts of exercise in the heat enhances subsequent performance. J Strength Cond Res. 2006;20(2):383-9
33. Armstrong LE, Crago AE, Adams R, Roberts WO, Maresh CM. Whole-body cooling of hyperthermic runners: comparison of two field therapies. Am J Emerg Med. 1996;14(4):355-8.

34. Lemire B, Gagnon D, Jay O, Dorman L, DuCharme MB, Kenny GP. Influence of adiposity on cooling efficiency in hyperthermic individuals. Eur J Appl Physiol. 2008;104(1):67-74.

35. Hausswirth C, Duffield R, Pournot H, Bieuzen F, Louis J, Brisswalter J, Castagna O. Postexercise cooling interventions and the effects on exercise-induced heat stress in a temperate environment. Appl Physiol Nutr Metab. 2012;37(5):965-75.

36. Dunne A, Crampton D, Egaña M. Effect of post-exercise hydrotherapy water temperature on subsequent exhaustive running performance in normothermic conditions. J Sci Med Sport. 2013;16(5):466-71.

37. Clapp AJ, Bishop PA, Muir I, Walker JL. Rapid cooling techniques in joggers experiencing heat strain. J Sci Med Sport. 2001:4(2):160-7.

38. Minett GM, Duffield R, Billaut F, Cannon J, Portus MR, Marino FE. Coldwater immersion decreases cerebral oxygenation but improves recovery after intermittent-sprint exercise in the heat. Scand J Med Sci Sports. 2014;24(4):656-66.

39. Peiffer JJ, Abbiss CR, Nosaka K, Peake JM, Laursen PB. Effect of cold water immersion after exercise in the heat on muscle function, body temperatures, and vessel diameter. J Sci Med Sport. 2009;12(1):91-6.

40. Peiffer JJ, Abbiss CR, Watson G, Nosaka K, Laursen PB. Effect of cold-water immersion duration on body temperature and muscle function. J Sports Sci. 2009;27(10):987-93.

41. Friesen BJ, Carter MR, Poirier MP, Kenny GP. Water immersion in the treatment of exertional hyperthermia: physical determinants. Med Sci Sports Exerc. 2014;46(9):1727-35

42. Lit KW, Chen CK, Ang BS. Effects of acute cool water immersion on time trial performance and exercised-induced oxidative stress among endurance cyclists in the heat. J Athl Enhancement. 2014:3:4

43. Robey E, Dawson B, Halson S, Goodman C, Gregson W, Eastwood P. Post-exercise cold water immersion: effect on core temperature and melatonin responses. Eur J Appl Physiol. 2013;113(2):305-11.

44. Vaile J, Halson S, Gill N, Dawson B. Effect of hydrotherapy on recovery from fatigue. Int J Sports Med. 2008;29(7):539-44.

45. Peiffer JJ, Abbiss CR, Watson G, Nosaka K, Laursen PB. Effect of a 5-min cold-water immersion recovery on exercise performance in the heat. $\mathrm{Br} J$ Sports Med. 2010;44:461-5.

46. Vaile J, O'Hagan C, Stefanovic B, Walker M, Gill N, Askew CD. Effect of cold water immersion on repeated cycling performance and limb blood flow. Br J Sports Med. 2011;45:825-9.

47. Taylor NA, Caldwell JN, Van den Heuvel AM, Patterson MJ. To cool, but not too cool: that is the question-Immersion Cooling for Hyperthermia. Med Sci Sports Exerc. 2008;40:1962-9.

48. Lee EC, Watson G, Casa D, Armstrong LE, Kraemer W, Vingren JL, Spiering BA, Maresh CM. Interleukin-6 responses to water immersion therapy after acute exercise heat stress: a pilot investigation. J Athl Train. 2012;47:655-63.

49. Gagnon D, Lemire B, Casa D, Kenny GP. Cold-water immersion and the treatment of hyperthermia: using $38.6^{\circ} \mathrm{C}$ as a safe rectal temperature cooling limit. J Athl Train. 2010;45:439-44.

50. Proulx C, Ducharme M, Kenny GP. Effect of water temperature on cooling efficiency during hyperthermia in humans. J Appl Physiol. 2003:94:1317-23.

51. Flouris AD, Friesen BJ, Carlson MJ, Casa DJ, Kenny GP. Effectiveness of cold water immersion for treating exertional heat stress when immediate response is not possible. Scand J Med Sci Sports. 2015;25(Suppl 1):229-39.

52. Demartini JK, Casa DJ, Stearns R, Belval L, Crago A, Davis R, Jardine J. Effectiveness of cold water immersion in the treatment of exertional heat stroke at the falmouth road race. Med Sci Sports Exerc. 2015;47(2):240-5.

53. Flouris AD, Wright-Beatty HE, Friesen BJ, Casa DJ, Kenny GP. Treatment of exertional heat stress developed during low or moderate physical work. Eur J Appl Physiol. 2014;114(12):2551-60.

54. Miller KC, Swartz EE, Long BC. Cold-Water Immersion for Hyperthermic Humans Wearing American Football Uniforms. J Athl Train. 2015;50(8):792-9.

55. Katica CP, Pritchett RC, Pritchett KL, Del Pozzi AT, Balilionis G, Burnham $T$. Effects of forearm vs. leg submersion in work tolerance time in a hot 
environment while wearing firefighter protective clothing. J Occup Environ Hyg. 2011;8:473-7.

56. Carter JM, Rayson MP, Wilkinson DM, Richmond V, Blacker S. Strategies to combat heat strain during and after firefighting. J Therm Biol. 2007:32:109-16.

57. Khomenok GA, Hadid A, Preiss-Bloom O, Yanovich R, Erlich T, Ron-Tal O, Peled A, Epstein Y, Moran DS. Hand immersion in cold water alleviating physiological strain and increasing tolerance to uncompensable heat stress. Eur J Appl Physiol. 2008;104(2):303-9.

58. Zhang Y, Nepocatych S, Katica CP, Collins AB, Casaru C, Balilionis G, Sjökvist J, Bishop PA. Effect of half time cooling on thermoregulatory responses and soccer-specific performance tests. Monten J Sports Sci Med. 2014;3(1):17-22.

59. Mittleman KD, Mekjavić IB. Effect of occluded venous return on core temperature during cold water immersion. J Appl Physiol. 1988;65(6):2709-13.

60. Howard RL, Kraemer WJ, Donald SC, Armstrong LE, Maresh CM. The effects of cold immersion on muscle strength. I Strength Cond Res. 1994;8(3):129-33.

61. Versey NG, Halson SL, Dawson BT. Water immersion recovery for athletes: effect on exercise performance and practical recommendations. Sports Med. 2013;43:1-30

62. Smith DL, Petruzzello SJ. Selected physiological and psychological responses to live-fire drills in different configurations of firefighting gear. Ergonomics. 1998;41(8):1141-54.

63. Castle PC, Macdonald AL, Philp A, Webborn A, Watt PW, Maxwell NS. Precooling leg muscle improves intermittent sprint exercise performance in hot, humid conditions. J Appl Physiol. 2006;100(4):1377-84.

64. Daanen HAM. Aterio-venous anastomoses and thermoregulation. Soesterberg: TNO Institute for Perception Group: Thermophysiology; 1991.

65. Taylor NA, Machado-Moreira CA, van den Heuvel AM, Caldwell JN. Hands and feet: physiological insulators, radiators and evaporators. Eur J Appl Physiol. 2014;114(10):2037-60.

66. Anon. Guideline 9.3.4-heat induced illness (hyperthermia): first aid management. Australian Resuscitation Council. 2008. http://resus.org.au/ guidelines/. Accessed 22 March 2015.

67. Kielblock AJ, Van Rensburg JP, Franz RM. Body cooling as a method for reducing hyperthermia. An evaluation of techniques. S Afr Med J. 1986;69(6):378-80.

68. Sinclair WH, Rudzki SJ, Leicht AS, Fogarty AL, Winter SK, Patterson MJ. Efficacy of field treatments to reduce body core temperature in hyperthermic subjects. Med Sci Sports Exerc. 2009;41(11):1984-90.

69. Cheung SS, Montie DL, White MD, Behm D. Changes in manual dexterity following short-term hand and forearm immersion in $10^{\circ} \mathrm{C}$ water. Aviat Space Environ Med. 2003;74(9):990-3.

70. White MD, Ross WD, Mekjavić IB. Relationship between physique and rectal temperature cooling rate. Undersea Biomed Res. 1992;19(2):121-30.
71. Perroni F, Cortis C, Minganti C, Cignitti L, Capranica L. Maximal oxygen uptake of Italian firefighters: laboratory vs. field evaluations. Sport Sci. Health. 2013;9:31-5.

72. Poston WSC, Haddock CK, Jahnke SA, Jitnarin N, Tuley BC, Kales SN. The prevalence of overweight, obesity, and substandard fitness in a population-based firefighter cohort. J Occup Environ Med. 2011;53:266-73.

73. Walker A, Driller M, Argus C, Cooke J, Rattray B. The ageing Australian firefighter: an argument for age based recruitment and fitness standards for urban fire services. Ergonomics. 2014;57:612-21.

74. Larose J, Boulay P, Wright-Beatty HE, Sigal RJ, Hardcastle S, Kenny GP. Agerelated differences in heat loss capacity occur under both dry and humid heat stress conditions. J Appl Physiol. 2014;117:69-79.

75. Larose J, Wright HE, Sigal RJ, Boulay P, Hardcastle S, Kenny GP. Do older females store more heat than younger females during exercise in the heat? Med Sci Sports Exerc. 2013;45:2265-76.

76. Kenney WL. A review of comparative responses of men and women to heat stress. Environ Res. 1985;37:1-11.

77. Sinden K, MacDermid J, Buckman S, Davis B, Matthews T, Viola C. A qualitative study on the experiences of female firefighters. Work. 2013:45:97-105.

78. McEntire SJ, Suyama J, Hostler D. Mitigation and prevention of exertional heat stress in firefighters: a review of cooling strategies for structural firefighting and hazardous materials responders. Prehosp Emerg Care. 2013:17:241-60

79. Casa DJ, McDermott BP, Lee EC, Yeargin SW, Armstrong LE, Maresh CM. Cold water immersion: the gold standard for exertional heatstroke treatment. Exerc Sport Sci Rev. 2007;35:141-9.

80. Smith RM, Hanna JM. Skinfolds and resting heat loss in cold air and water: temperature equivalence. J Appl Physiol. 1975;39(1):93-102.

81. Casa DJ, Kenny GP, Taylor NA. Immersion treatment for exertional hyperthermia: cold or temperate water? Med Sci Sports Exerc. 2010;42(7):1246-52.

82. Cheung SS, Petersen SR, McLellan TM. Physiological strain and countermeasures with firefighting. Scand J Med Sci Sports. 2010;20(Suppl 3):103-16.

83. DeGroot DW, Gallimore RP, Thompson SM, Kenefick RW. Extremity cooling for heat stress mitigation in military and occupational settings. J Therm Biol. 2013;38(6):305-10.

84. Brearley M, Norton I, Kingsbury D, Maas S. Responses of elite road motorcyclists to racing in tropical conditions: a case study. Int I Sports Physiol Perform. 2014;9(5):887-90

85. Manson P. Tropical diseases: a manual of the diseases of warm climates. London: Cassell; 1898. p. 118.

\section{Submit your next manuscript to BioMed Central and take full advantage of:}

- Convenient online submission

- Thorough peer review

- No space constraints or color figure charges

- Immediate publication on acceptance

- Inclusion in PubMed, CAS, Scopus and Google Scholar

- Research which is freely available for redistribution 